\title{
Gestão de Recursos Humanos No Contexto Internacional: Um Estudo Comparativo Entre Duas Empresas Multinacionais
}

\author{
Shalimar Gallon \\ Faculdade Meridional - IMED - Brasil \\ shalimargallon@gmail.com \\ Betina Magalhães Bitencourt \\ Universidade Estadual do Rio Grande do Sul - Brasil \\ betina.mb@gmail.com \\ Claudia Cristina Bitencourt \\ UNISINOS - Brasil \\ claucbitencourt@gmail.com \\ Vitor Francisco Dalla Corte \\ Faculdade Meridional - IMED Business School - Brasil \\ vitor.corte@imed.edu.br
}

\begin{abstract}
Resumo
Esse estudo analisa as configurações da Gestão de Recursos Humanos das empresas portuguesas e brasileiras no que concerne aos negócios internacionais visto a importância de entender essa área frente às mudanças do contexto global. Para tanto, foi realizado um estudo de caso qualitativo em uma multinacional brasileira e uma portuguesa, nas quais foram realizadas 30 entrevistas com base em um roteiro semiestruturado. As entrevistas foram analisadas pela técnica de análise de conteúdo com o auxílio do software Max-Qda (2007) na organização das categorias de análise. Os dados sinalizam que a empresa portuguesa tem uma estrutura de GRH mais consolidada, apresentando uma GRH global desvinculada da matriz da empresa. Já a GRH da empresa brasileira está se desenvolvendo e mostrou, em momentos pontuais, iniciativas de fomentar e disseminar práticas globais. No entanto, a empresa brasileira mostra amadurecer lentamente no contexto internacional, muito em função da sua perspectiva etnocêntrica na GRH, a qual envia as diretrizes para as subsidiárias no exterior.
\end{abstract}


p. 66-101

Palavras-Chave: expatriação, gestão de recursos humanos estratégica, gestão de recursos humanos internacional, internacionalização 


\title{
Human Resource Management In International Context: A Comparative Study Between Two Multinational Companies
}

\author{
Shalimar Gallon \\ Faculdade Meridional - IMED - Brasil \\ shalimargallon@gmail.com \\ Betina Magalhães Bitencourt \\ Universidade Estadual do Rio Grande do Sul - Brasil \\ betina.mb@gmail.com \\ Claudia Cristina Bitencourt \\ UNISINOS - Brasil \\ claucbitencourt@gmail.com \\ Vitor Francisco Dalla Corte \\ Faculdade Meridional - IMED Business School - Brasil \\ vitor.corte@imed.edu.br
}

\begin{abstract}
This study aims to analyze the settings of the Human Resources Management of Portuguese and Brazilian companies regarding international businesses. Its relevance lies on understanding this area in a changing global context. Therefore, a qualitative case study was conducted in a Brazilian and Portuguese multinational companies, in wich 30 interviews were conducted based on a semi-structured script. The interviews were analysed by content analysis technique, and Max-QDA software (2007) was used to assist in the categories of analysis organization. The results indicate that the Portuguese company has a consolidated HRM structure, presenting a global HRM detached from the parent company. The HRM of the Brazilian company is developing and has shown, at specific moments, initiatives to promote and disseminate global practices. However, the Brazilian company shows slowly mature in the international context, much due to its ethnocentric HRM, which sends the guidelines to subsidiaries abroad.
\end{abstract}

Keywords: expatriation, strategic human resource management, international human resource management, internationalization 
A estratégia empresarial no contexto internacional tem impactado a Gestão de Recursos Humanos (GRH) ao sinalizar a mudança de um enfoque local para uma visão global. Há a necessidade de gerir globalmente, como se o mundo constituísse um grande mercado e, simultaneamente, gerir localmente, em um mundo com mercados separados, mas interligados (Bartlett \& Ghoshal, 1998; Schuler, Budhwar, \& Florkowski, 2002).

Em termos de estrutura, existem a GRH doméstica e a GRH Internacional (GRHI), que é o meio de ligação entre as unidades (Boxall et al., 2007). A GRHI assume o processo de expatriação e deve ter conhecimento das condições dos vários países e de como gerir trabalhadores de diferentes nacionalidades. Para isso, deve incluir a perspectiva dos empregados de todos os contextos, mesmo que isso implique a integração de culturas contrastantes ou distantes (Schuler, Dowling, \& De Cieri, 1993).

Nesse contexto, emergem diferentes orientações - etnocêntrica, policêntrica, geocêntrica ou regiocêntrica (Vance \& Paik, 2006) -, bem como diferentes configurações doméstica, internacional, global, estratégica, comparativa, corporativa (Boxall et al., 2007; Schuler, 2000; Schuler et al., 2002; Taylor, Beechler, \& Napier, 1996) para a GRH. Assim, indaga-se: como está estruturada a GRH em empresas internacionalizadas?

Para tanto, o presente estudo ressalta a importância da GRH com atuação estratégica (Ulrich, 2000; Schuler, 2000), principalmente no que concerne aos negócios internacionais, sobretudo devido à necessidade de melhor compreender as questões associadas ao gerenciamento de pessoas em um contexto global e de avançar em seu conhecimento (Schuler, 2000). Assim, este estudo buscou analisar as configurações da GRH na internacionalização de empresas em duas organizações multinacionais: uma brasileira e uma portuguesa. O estudo foi oportuno visto a proximidade cultural e linguística dos dois países, além do vínculo histórico, que permitiram que a investigação fosse mais rica e aprofundada.

Estudos nacionais e internacionais apontam sobre a importância de se pesquisar a GRH Estratégica (GRHE) e as estruturas da GRH (M. L. Lengnick-Hall, C. A. Lengnick-Hall, Andrade, \& Drake, 2009; Armond et al., 2016) visando um amadurecimento do campo e a consolidação dos estudos nacionais. Também é apontado que há um espaço para o desenvolvimento de pesquisas em GRHI (Schuler, 2000) com embasamento consolidado, visto que os estudos desenvolvidos são excessivamente descritivos e, por consequência, sem suficiente rigor analítico e teórico (McDonnell, Stanton, \& Burgess, 2011; Bianchi, 2011). Ademais, a maioria dos estudos em GRHI está centrada na transferência de práticas de GRH 
entre matriz e subsidiária (McDonnell et al., 2011), bem como na expatriação e suas práticas (Smale, 2008; McDonnell et al., 2011) focando no indivíduo em vez de na organização como unidade de análise (McDonnell et al., 2011).

Ademais, salienta-se a carência de estudos em economias emergentes (Schuler et al., 2002; Bianchi, 2011; McDonnell et al., 2011), principalmente, no que concerne aos estudos de internacionalização de empresas (Bartlett \& Ghoshal, 2006; McDonnell et al., 2011) ) a fim de avançar o conhecimento de como as empresas operam, se comportaram e o impacto do controle da matriz na GRH da subsidiária (McDonnell et al., 2011), comparando a GRH em diferentes países (Kim \& Gray, 2005). Além disso, é importante desenvolver pesquisas que mostrem a realidade de outros países e confrontem os resultados com a perspectiva anglo-saxônica para analisar as diferenças e semelhanças entre os estudos e as correntes mais tradicionais e hegemônicas (Pudelko \& Harzing, 2007; McDonnell et al., 2011; Bianchi, 2011).

A seguir, é apresentada a literatura sobre GRH e GRHI, a partir da perspectiva estratégica, além dos procedimentos metodológicos de pesquisa. Na quarta seção, é exposta a análise de dados e as implicações do estudo. Por fim, as considerações finais, limitações da pesquisa e sugestões de estudos futuros compõem as últimas seções do artigo.

\section{Gestão de Recursos Humanos e Internacionalização}

Tendo em vista a sua importância estratégica, há três importantes divisões da GRH: micro GRH; GRHE; e GRHI (Boxall et al., 2007). A complexidade de operar em diferentes países, empregando pessoas de diferentes nacionalidades é uma variável-chave, a qual diferencia a micro GRH da internacional. A diferenciação dessas duas áreas liga a GRH a questões estratégicas das multinacionais (Schuler, 2000), sendo esse o papel da GRHE.

O desafio das organizações, portanto, é se adaptar às diversas práticas e criar uma gestão apropriada às diferentes culturas. Surge, consequentemente, a GRH comparativa (Schuler, 2000) que desenvolve e administra as políticas e práticas, em uma ampla variedade de nações, cada uma com suas próprias características legais, econômicas, políticas, sociais e culturais (Schuler et al., 2002). Por isso, a interação entre a matriz e as subsidiárias é um aspecto de destaque na literatura sobre internacionalização (McDonnell et al., 2011). 
Para além das limitações dos estudos e das organizações em gerenciar esse tema, cabe à reflexão em como a GRH é globalmente integrada nas subsidiárias ou, pelo menos, indica a necessidade dessa integração (Schuler, 2000; Schuler et al., 1993; Smale, 2008). Para tanto, a GRH comparativa não deve buscar uma simples padronização como uma adoção mundial de práticas. As empresas devem buscar a disseminação das melhores práticas, de onde elas originam; se as práticas da matriz são bem-sucedidas, estas devem ser cuidadosamente exploradas em toda a organização e as práticas da matriz devem prevalecer; se, no entanto, as práticas das subsidiárias se mostrarem superiores, estas devem ser a fonte de inspiração (Pudelko \& Harzing, 2007). Assim, dizer que uma prática é global significa ser mais do que ser comum a todas as empresas; a prática tem que ser encaixada como um sistema e que existem processos que a difundem globalmente (Edwards et al., 2013).

A importância de se repensar a GRH global tem destaque quando se olha as práticas de GRH que estão sendo implantadas isoladamente. Pesquisas mostram que os gestores das subsidiárias mobilizam recursos dentro e fora da empresa multinacional de acordo com o que julgam estratégico para a sua gestão de carreira. Assim, o gestor negligencia ou prejudica interesses vitais da subsidiária para o bem da progressão de sua carreira na matriz. Daí a importância de a matriz projetar tanto um plano como oportunidades de carreira para os gerentes, a fim de influenciá-los nas orientações estratégicas e nas relações de troca de recursos com a subsidiária (Becker-Ritterspach \& Dörrenbächer, 2011; Dörrenbächer \& Geppert, 2009), bem como na implantação de políticas e práticas de GRH em âmbito global e não de maneira pontual em cada subsidiária.

Ao se analisar a estrutura da GRH em mais de mil empresas do Canadá, Irlanda, Espanha e Reino Unido, não foi encontrada significativa presença de uma estratégia global, pois a área teve apenas um impacto limitado, sendo mais perceptível uma pequena presença da perspectiva global na área de produção. No geral, os resultados mostram que o tamanho, integração e estrutura da empresa, bem como a presença de uma GRHI desempenham um papel importante na implantação das práticas de GRH. Todas as evidências internacionais apontam para uma aceitação limitada das práticas de GRH e seria notável se as multinacionais adotassem um modelo específico de GRH para todas as subsidiárias. Pode não haver um conjunto único de melhores práticas, mas também há uma adoção generalizada de algumas práticas específicas. As subsidiárias da matriz podem responder ao ambiente institucional de um país, implantando um número expressivo de novas práticas. É importante, portanto, que haja um conjunto de melhores práticas de GRH que sejam 
amplamente difundidas e não limitadas por efeitos sociais ou fatores específicos (Edwards et al., 2013).

O citado estudo mostra evidências de que há uma maior adoção de práticas de GRH nas multinacionais de sistemas empresariais bem definidos, aqueles que são claramente economias de mercado liberais ou coordenados (instituições sociais e políticas, incluindo atores do mercado de trabalho, como sindicatos). É apontando que o incentivo a adoção de práticas de GRH são influenciadas pelo contexto e não pela natureza da empresa (Edwards et al., 2013). As empresas têm uma escolha considerável e precisam configurar as práticas de GRH para atender às demandas diárias e também atender aos objetivos estratégicos. Assim, a GRH tem um papel mais ativo do que às vezes é lhe atribuído (Edwards et al., 2013).

No contexto internacional, a empresa pode adotar uma estratégia de GRH etnocêntrica, policêntrica, geocêntrica ou regiocêntrica (Vance \& Paik, 2006). Na perspectiva etnocêntrica, as principais tomadas de decisão são realizadas na matriz (Vance \& Paik, 2006). As empresas procuram transferir o conhecimento para as subsidiárias, pois é a maneira de replicar, em outros países, as vantagens desenvolvidas sobre seus concorrentes locais (Oliveira \& Borini, 2010), tendo, assim, a gestão do conhecimento destaque na ampliação dos negócios globais (Smale, 2008) e sinalizando uma maturidade internacional das empresas (Bartlett \& Ghoshal, 2000).

A dificuldade em amadurecer globalmente está relacionada ao isomorfismo institucional, na qual as multinacionais estão imersas em pressupostos, práticas e instituições do sistema nacional de negócios do qual surgiram (Quintanilla, Susaeta, \& Sanchez-Mangas, 2008). A empresa, ao invés de buscar conciliar a diversidade para criar uma corporação global, impõe o planejamento único nas subsidiárias. Por isso, muitas empresas não conseguem ter suas estratégias globais bem-sucedidas, pois suas políticas e práticas são impositivas e não globalmente construídas (Quintanilla et al., 2008), diminuindo a possibilidade de as multinacionais acumularem experiência internacional (Ando, 2011). Assim, as multinacionais têm dificuldade em mudar suas rotinas (Ando, 2011) e tendência a continuarem com as operações de forma centralizada e com a gestão de processos, políticas e sistemas formais e padronizados (Quintanilla et al., 2008), para se beneficiar das vantagens da matriz, além de ser uma forma de controle e coordenação, visto o desafio em equilibrar o global/ local nas práticas de gestão (Pudelko \& Harzing, 2007; Bartlett \& Ghoshal, 1998; Schuler et al., 2002; Smale, 2008; Quintanilla et al., 2008). 
Tal panorama é percebido nas empresas brasileiras visto o fluxo mais intenso da transferência de conhecimento da matriz para as subsidiárias, destacando-se o papel do expatriado (Oliveira \& Borini, 2010). O envio de expatriados é utilizado como um recurso estratégico para facilitar a transferência de conhecimento (Wang, Tong, Chen, \& Kim, 2009; Vance \& Paik, 2006), implantar a cultura e objetivos corporativos (Kim \& Gray, 2005), melhorar o desempenho do investimento no exterior (Wang et al., 2009), prevenir o vazamento de informações importantes e proteger o know-how tecnológico (Vance \& Paik, 2006).

Estudos mostram que quando a subsidiária aumenta em tamanho, a autonomia da subsidiária também aumenta. No contraponto, a autonomia diminui quando o tamanho da subsidiária torna complexo na perspectiva da matriz (Johnston \& Menguc, 2007). Outro estudo aponta que as subsidiárias têm diferentes estruturas de acordo com o seu papel definido dentro da estrutura corporativa da matriz (Lee \& Williams, 2007), o que implica em diferentes práticas de GRH. As subsidiárias que desempenham um papel de maior valor agregado estão mais propensas a serem fontes de novas práticas para a matriz implantar em outros países (Lee \& Williams, 2007).

No entanto, outros estudos sugerem que não há correlação direta entre a estratégia internacional e a estratégia de GRH da subsidiária, pois existem outros fatores para entender essa relação (Kim \& Gray, 2005). A justificativa para isso é que: (1) o grau relativamente baixo de transferência global suporta a afirmação geral de que a GRH está localizada para refletir diferenças em ambientes regulatórios e culturais entre os países de origem e os países de acolhimento. O baixo grau de transferência consistentemente encontrado em todas as práticas de GRH reflete a necessidade de as multinacionais modificarem a GRH nas subsidiárias para atingir um nível de isomorfismo com as instituições ambientais dos países de acolhimento; (2) a GRHI foi configurada, em graus variados, por fatores estratégicos. Entre as variáveis investigadas, as funções das subsidiárias influenciaram significativamente o grau de transferência. Este resultado mostra que a extensão e o tipo de controle são diferenciados de acordo com o papel da subsidiária de uma maneira que reflete o poder relativo da subsidiária em uma rede de recursos dentro da matriz; e (3) o ajuste da GRHI com as necessidades estratégicas da matriz está em parte refletido no apoio parcial à ligação entre GRHI e a estratégia corporativa internacional (Kim \& Gray, 2005).

Uma orientação etnocêntrica pode, entretanto, levar à miopia cultural ou a uma falha na compreensão das diferenças do país anfitrião. Neste caso, a orientação policêntrica é mais 
coerente, pois requer profissionais locais para participar da gestão. Este tipo de prática está associada ao particularismo cultural, que valoriza a distinção entre países, pois os trabalhadores nativos estão familiarizados com a cultura local, além de possuírem maior rede de contatos. Em contraste com expatriados, estes gestores locais possuem elevado grau de competência local, mas, normalmente, baixo grau de competência corporativa (Vance \& Paik, 2006).

A orientação geocêntrica pressupõe que os empregados mais qualificados devem ocupar cargos gerenciais importantes, independente da nacionalidade. Essa abordagem é atraente em empresas com estrutura organizacional interdependente, pois elimina a hierarquia de influência e facilita a criação de uma empresa internacional que se identifica com os interesses de ambos os países, permitindo o desenvolvimento das melhores pessoas para as melhores posições. As empresas que seguem esta orientação tendem a ter uma cultura corporativa mais unificada, além de um gerenciamento de informações mais eficaz (Vance \& Paik, 2006).

Já a orientação regiocêntrica promove a interação entre expatriados transferidos para as subsidiárias no mesmo país. Esta abordagem pode ser benéfica para as empresas que não têm gestores globais treinados - realidade presente em muitas organizações (Rego \& Cunha, 2009; McDonnell et al., 2011) -, pois permite que os gerentes, em diferentes localizações e níveis, tornem-se membros de redes informais, com base nessas relações estabelecidas (Vance \& Paik, 2006).

Essa nomenclatura permite entender como as diversas configurações de expatriados estão ligadas à estratégia de internacionalização e a orientação de GRH da empresa. No modelo geocêntrico, há mais possibilidades para expatriados com uma carreira organizacional mais madura (Mccall \& Hollenbeck, 2003). Assim, o planejamento da GRH em âmbito internacional, a estratégia internacional e a estrutura de uma empresa podem afetar diretamente o número e a configuração dos cargos internacionais e de expatriados (Mccall \& Hollenbeck, 2003).

Um dos desafios da GRHI, portanto, é o uso estratégico de expatriados, pois, nas missões internacionais, estes empregados adquirem competências que lhes permitem equilibrar a integração global e local e, consequentemente, alterar o posicionamento da GRH (etnocêntrico, policêntrico, geocêntrico e regiocêntrico). Ademais, a GRHI deve fomentar o uso de diferentes configurações de expatriados, tais como os impatriados - empregados das subsidiárias que trabalham em missões na matriz da empresa e que vão com o intuito de 
aprender a cultura da empresa matriz e levá-la para a subsidiária (Harvey et al., 2000; Rego \& Cunha, 2009) -; repatriados - expatriado que retorna para a empresa matriz (Gallon \& Antunes, 2013) -; patriado - empregado que retorna para a empresa, depois de uma sequência de múltiplas realocações (Harvey \& Novicevic, 2006) -; flexpatriados - empregado que circula entre países, em estadas de curta duração (Rego \& Cunha, 2009) -; autoexpatriados - profissionais que fazem a sua própria expatriação sem o auxílio de um meio facilitador no estrangeiro (Nardi, 2015; Dickmann \& Doherty, 2008) -; cidadão do mundo - pessoa que transita por diversos países, se adapta facilmente a outras culturas e já perdeu a identidade de cidadão de um único país (Freitas \& Dantas, 2011) -; e empregado transnacional - lida com pessoas de várias origens culturais (McCall \& Hollenbeck, 2003; Tanure, Evans, \& Pucik, 2007; Rego \& Cunha, 2009).

Por todo exposto, o entendimento da perspectiva local e global ultrapassa as questões territoriais. O fato de a empresa atuar no território estrangeiro não necessariamente significa que ela seja uma empresa global. Há, portanto, a necessidade de coordenar as operações no exterior para garantir a contribuição à estratégia empresarial integrada. A perspectiva global surge quando a organização passa a planejar as estratégias dentro de um contexto mais amplo (Bartlett \& Ghoshal, 1998; Schuler et al., 2002). As empresas são, consequentemente, obrigadas a reconhecer a crescente necessidade de flexibilidade estratégica para serem proativas e responder rapidamente às mudanças nas condições organizacionais e ambientais, bem como a necessidade de ajuste estratégico entre a GRHI e a organização (Kim \& Gray, 2005; De Ré \& De Ré, 2011; Richey \& Wally, 1998), emergindo, portanto, a necessidade de pesquisar a GRH no contexto internacional.

\section{Procedimentos Metodológicos}

O presente estudo utilizou como estratégia de pesquisa o estudo de caso (Yin, 2010) de caráter qualitativo. A pesquisa foi realizada na empresa brasileira Elétrica (sua matriz no Brasil e sua subsidiária em Portugal) e na empresa portuguesa Plástico (sua matriz em Portugal e sua subsidiária no Brasil) (nomes fictícios). As empresas foram escolhidas, pois ambas têm destaque no país de origem; pertencem ao setor industrial; estão internacionalizadas há mais de 20 anos; e encontram-se presentes em diversos países. A escolha por Portugal decorreu da aproximação cultural e linguística com o Brasil. 


\section{Coleta de Dados}

A coleta de dados começou em um estudo exploratório com gestores e expatriados brasileiros e portugueses no intuito de fazer um levantamento sobre o panorama da GRH no contexto internacional e da expatriação em organizações internacionais, bem como entender o contexto português. As empresas portuguesas que participaram do estudo exploratório foram Grupo Turismo (Lisboa), Empresa Energia (Lisboa), Empresa Cimento (Lisboa) e Empresa Exportação (Lisboa). Em cada empresa foi entrevistada uma pessoa, a fim de melhor compreender o processo de internacionalização e a relação com a expatriação. Já as empresas brasileiras pesquisadas foram Metálica (Rio Grande do Sul) e Ferro (Rio Grande do Sul). Na Metálica, foram entrevistadas três pessoas e, na Ferro, duas. Também foi entrevistada uma consultora em intercâmbio cultural, com renome na área sobre mobilidade internacional em grandes empresas.

Pela pesquisa demandar um público específico (profissionais expatriados para Portugal ou Brasil e que tivessem conhecimento ou contato com a expatriação, GRH, estratégia, internacionalização ou com os países pesquisados), o número de pessoas disponíveis mostrou-se reduzido. Não foi, portanto, usado nenhum critério adicional na escolha dos entrevistados (como sexo, idade ou cargo). Todas as pessoas indicadas foram contatadas para participarem da pesquisa, cabendo a elas aceitarem ou não participar do estudo. Assim, também fizeram parte da pesquisa os expatriados que estavam em outras subsidiárias, fora do contexto Portugal-Brasil, mas que tiveram experiência internacional.

A coleta dos dados foi realizada por meio de entrevista semiestruturada, com base no roteiro desenhado a partir do referencial teórico e foi construído conforme o campo foi sendo explorado. Foram utilizadas ferramentas de conversação via internet, como o Skype que oferece a possibilidade de realização de entrevistas individuais (Janghorban, Roudsari, \& Taghipour 2014), para auxiliar na condução das entrevistas ou para retomar algum ponto que precisava ser esclarecido, encontrando-se a pessoa a grande distância. Essas ferramentas permitem comunicação com respondentes dispersos geograficamente e são de uso cotidiano aos entrevistados (Janghorban et al., 2014).

A coleta de dados começou no Brasil em 2012, com o estudo exploratório e, de julho a outubro de 2013 foi realizada a coleta de dados em Portugal (entrevistados coadjuvantes e protagonistas das empresas portuguesas). Em novembro e dezembro de 2013 foram realizadas as entrevistas no Brasil. No total, foram analisadas 31 entrevistas: uma foi 
realizada pelo Jornal i (2011), em 12.12.2011, sendo assim, um dado secundário e 30 são dados primários. Desses dados primários, 11 entrevistados atuavam na GRH; 17 entrevistados eram expatriados; e 17 entrevistados eram gestores, considerando que alguns entrevistados eram da GRH e expatriado, gestor e expatriado ou da GRH e gestor. Nenhum dos entrevistados era da GRH, gestor e expatriado (Tabela 1).

Tabela 1

Quantidade de entrevistados por empresa, nacionalidade e atuação organizacional

\begin{tabular}{|c|c|c|c|}
\hline Sujeitos & Plástico & Elétrica & Gestores \\
\hline Entrevistas em Portugal & 3 & 4 & 5 \\
\hline Entrevistas no Brasil & 5 & 5 & 6 \\
\hline Entrevistas no Skype & $\mathrm{O}$ & 1 & 1 \\
\hline $\begin{array}{l}\text { Total de Entrevistas (local de } \\
\text { coleta) }\end{array}$ & 8 & 10 & 12 \\
\hline Portugueses & 6 & 1 & 5 \\
\hline Brasileiros & 2 & 9 & 7 \\
\hline $\begin{array}{l}\text { Total } \quad \text { de } \\
\text { (nacionalidade) }\end{array}$ & 8 & 10 & 12 \\
\hline GRH & 4 & 2 & 3 \\
\hline GRH e Gestor & $\mathrm{O}$ & 1 & $\mathrm{O}$ \\
\hline GRH e Expatriado & $\mathrm{O}$ & $\mathrm{O}$ & 1 \\
\hline Gestor & O & $\mathrm{O}$ & 3 \\
\hline Expatriado e Gestor & 3 & 6 & 4 \\
\hline Expatriado & 1 & 1 & 1 \\
\hline $\begin{array}{l}\text { Total de Entrevistas (atuação } \\
\text { organizacional) }\end{array}$ & 8 & 10 & 12 \\
\hline
\end{tabular}

Fonte: Elaborada pelos autores (2017).

Além das entrevistas, foram realizadas consultas a documentos, sites e material publicitário, com o objetivo realizar a triangulação dos dados, para melhor compreender o fenômeno estudado (Yin, 2010).

\section{Análise de Dados}

Após a coleta de dados, foi realizada a transcrição das entrevistas e utilizada a técnica de análise de conteúdo (Bardin, 2009). A análise partiu de quatro macrocategorias a priori: GRH, internacionalização, expatriação e diferenças entre os países, visto que esses foram os 
temas norteadores da pesquisa. Em seguida, foi realizada uma leitura flutuante das entrevistas para organizar as informações dentro das categorias elencadas.

A partir disso, desenvolveu-se o procedimento de análise categorial, no qual é fornecido o sistema de categorias e os dados são distribuídos, da melhor maneira possível, à medida que vão sendo encontradas as relações (Bardin, 2009). Assim, conforme o trabalho de categorização era desenvolvido, as categorias iniciais e intermediárias foram surgindo naturalmente e sendo organizadas nas macrocategorias (Quadro 1), tendo como pano de fundo o referencial teórico abordado. Para organização e reestruturação das categorias foi utilizado o software Max-Qda versão 2007 que auxiliou a comparação dos estudos de caso, possibilitando melhor visualização dos dados.

\begin{tabular}{|c|c|}
\hline Categorias Intermediárias & Categorias Finais \\
\hline Estrutura da GRH & \multirow{2}{*}{$\begin{array}{l}\text { Gestão de Recursos } \\
\text { Humanos }\end{array}$} \\
\hline Orientação da GRH & \\
\hline $\begin{array}{l}\text { Estratégia } \\
\text { Internacionalização }\end{array}$ & \multirow[t]{2}{*}{ Gestão Internacional } \\
\hline Modelo de Internacionalização & \\
\hline $\begin{array}{l}\text { Conceitos e Configurações de } \\
\text { Expatriação }\end{array}$ & \multirow[t]{2}{*}{ Processo de Expatriação } \\
\hline Práticas de Expatriação & \\
\hline Fatores Econômicos - Legais & \multirow{2}{*}{$\begin{array}{l}\text { Diferenças entre Portugal } \\
\text { e Brasil }\end{array}$} \\
\hline Fatores Culturais & \\
\hline
\end{tabular}

Quadro 1. Categorias da pesquisa

Fonte: Elaborado pelos autores (2017).

\section{Análise da Gestão de Recursos Humanos na Empresa Elétrica e Plástico}

Os principais conceitos abordados na categoria de GRH (Quadro 2) estão associados as categorias iniciais que emergiram dos estudos de casos analisados. A fim de sintetizar os achados, as duas categorias intermediárias são apresentadas juntamente com a análise da categoria final de GRH. A partir disso, a análise da GRH da Elétrica é apresentada na próxima seção, seguida da análise da GRH da Plástico.

\begin{tabular}{|l|l|l|}
\hline Categorias & \multicolumn{1}{|c|}{$\begin{array}{c}\text { Categorias Iniciais - } \\
\text { Empresa Portuguesa }\end{array}$} & \multicolumn{2}{c|}{$\begin{array}{c}\text { Categorias Iniciais - Empresa } \\
\text { Brasileira }\end{array}$} \\
\hline $\begin{array}{l}\text { Estrutura } \\
\text { da GRH }\end{array}$ & $\begin{array}{l}\text { Importância da GRH; GRH } \\
\text { operacional; práticas globais; } \\
\text { GRHI; GRH global; GRH }\end{array}$ & $\begin{array}{l}\text { GR corporativa; GRH brasileira } \\
\text { estrurada; GRH Giência de comunicação da GRHI. }\end{array}$ \\
\hline
\end{tabular}




\begin{tabular}{|c|c|c|}
\hline Categorias & $\begin{array}{l}\text { Categorias Iniciais - } \\
\text { Empresa Portuguesa }\end{array}$ & $\begin{array}{c}\text { Categorias Iniciais - Empresa } \\
\text { Brasileira }\end{array}$ \\
\hline & $\begin{array}{l}\text { corporativa; GRH estratégica; } \\
\text { circulação de pessoas. }\end{array}$ & \\
\hline $\begin{array}{l}\text { Orientação } \\
\text { da GRH }\end{array}$ & $\begin{array}{ll}\text { GRH policêntrica; } & \text { GRH } \\
\text { etnocêntrica; } & \text { GRH } \\
\text { geocêntrica. } & \end{array}$ & \begin{tabular}{lrr} 
GRH etnocêntrica & das & unidades \\
brasileiras; & GRH & corporativa \\
etnocêntrica; & GRH & portuguesa \\
policêntrica; & \multicolumn{2}{c}{ amadurecimento } \\
corporativo policêntrico.
\end{tabular} \\
\hline GRH & $\begin{array}{l}\text { - Início da internacionalização } \\
\text { com GRH etnocêntrica; } \\
\text { - Com o desenvolvimento } \\
\text { internacional, a GRH é } \\
\text { etnocêntrica ou policêntrica, } \\
\text { conforme o contexto; e } \\
\text { - Com a GRH global, há } \\
\text { sinalização de um } \\
\text { posicionamento geocêntrico. }\end{array}$ & $\begin{array}{l}\text { - GRH centralizada na matriz e } \\
\text { acompanha lentamente } \\
\text { internacionalização da empresa; } \\
\text { - GRH corporativa sem perspectiva global; } \\
\text { - GRH policêntrica nas unidades } \\
\text { internacionais; } \\
\text { - Elétrica Knowledge com conhecimento } \\
\text { informativo e etnocêntrico; e } \\
\text { - Necessidade de uma GRH global e uma } \\
\text { GRHE para a expansão da empresa. }\end{array}$ \\
\hline
\end{tabular}

Quadro 2. Ideias norteadoras dos estudos de casos português e brasileiro Fonte: Elaborado pelos autores (2017).

\section{Análise da Gestão de Recursos Humanos da Empresa Elétrica}

Fundada em 1961, a Elétrica é uma empresa de capital brasileiro, líder na América Latina e está entre as maiores empresas do mundo na fabricação de elétricos industriais. Tem 14 empresas fabris no Brasil, 14 empresas no exterior e 22 instalações de distribuição e comercialização, além de representantes em mais de 100 países, nos cinco continentes (Empresa Elétrica, 2011). A sua internacionalização começou em 1988 por meio de exportações, sendo que a primeira filial surgiu, em 1991, nos EUA. Em 2007, a empresa tinha como meta ser a maior fabricante de elétricos industriais do mundo e, para atingir esse objetivo, em 2002, adquiriu a empresa Motores, em Portugal.

Ao analisar a estrutura da GRH da matriz, o E11 (Diretor de GRH Corporativa Brasil) relata que ela é "corporativa e está estreitamente relacionada com as decisões da matriz”, tendo como função de "se reportar diretamente ao presidente da empresa e prestar serviços para as outras áreas" (E16 - Analista de GRHI Brasil). Para atender os 22 mil empregados no Brasil, a GRH corporativa é percebida como estruturada, visto que a empresa "tem mapeado todos os processos de GRH: têm 30 e poucos processos e 400 e tantos subprocessos de GRH” (E16 - Analista de GRHI Brasil). 
As unidades brasileiras têm a sua própria GRH, mas há um posicionamento etnocêntrico (Vance \& Paik, 2006) por parte da matriz. A matriz centraliza as tomadas de decisões e a definição das políticas e práticas (Quintanilla et al., 2008), enquanto a GRH das unidades brasileiras desenvolvem o papel operacional para atender as necessidades diárias da empresa.

A estrutura da GRH das subsidiárias no exterior não é coerente com a realidade das subsidiárias brasileira, embora haja algumas unidades mais desenvolvidas e que mantêm um relacionamento mais próximo com a matriz. Esse não é o panorama da GRH da subsidiária portuguesa, a qual ainda apresenta concepções da cultura do antigo proprietário, como relata a E18 (Analista de GRH Europa): "estava muito ligada à Motores. Fomos criando, desde o departamento, fazer exatamente os procedimentos costumeiros, de forma a dar a abertura da GRH. O que tinha aqui, até então, não era GRH”. Assim, a GRH das unidades internacionais se mostrou mais autônoma para a criação das políticas e práticas e tem, na matriz, uma empresa de consultoria para disponibilizar as ferramentas.

Essa perspectiva policêntrica (Vance \& Paik, 2006) é coerente com a pequena estrutura da GRH das subsidiárias implicando no desenvolvimento de práticas pontuais, bem como em uma lenta disseminação das práticas. O E13 (Vice-Presidente EUA) relata que a unidade dos EUA "tem uma gerente de GRH, tem uma equipe de GRH com ela, que tem uma estrutura por trás dela. Ela tem desde planos de cargos e salários até a parte de bônus e avaliação e tem um software que ajuda. Eu diria até que, em algumas coisas, a gente está um pouquinho melhor que o Brasil, apesar da gente não ter a estrutura do Brasil”. Como não há uma gestão que propicie a troca de informações, as práticas que são mais bem conduzidas na unidade dos EUA acabam não sendo aproveitadas na empresa como um todo. Isso contraria as pesquisas que mostram que dependendo da importância que a subsidiária tem dentro das estratégias globais, elas estariam mais propensas a serem fontes de novas práticas para a matriz implantar em outros países (Lee \& Williams, 2007).

Em relação à GRHI, a E18 (Analista de GRH Europa) observa a ausência dessa área, nem para receber os expatriados. $\mathrm{O}$ diretor ou o gerente direto do expatriado da subsidiária portuguesa é quem fica responsável pela recepção dos expatriados e por algumas tramitações a eles pertinentes. Logo, sem a formalização da GRHI da subsidiária, suas funções são assumidas pela GRH doméstica e, de modo informal, pelos gestores.

Tal contexto é corroborado com o depoimento do E14 (Assistente Técnico Europa) ao relatar que a GRH portuguesa o auxiliou nos processos burocráticos, como na obtenção de 
documentos. Os depoimentos dos expatriados em Portugal (E10, E12 e E17) compartilham dessa percepção e sinalizam a fraca atuação da GRHI - da matriz e da subsidiária - frente às necessidades dos expatriados. O E10 (Supervisor de vendas internacionais Brasil), um dos primeiros expatriados para Portugal, relata um descontentamento com a GRH da subsidiária há dez anos: "a GRH de Portugal era fraca já na Motores, imagina para suportar nós ali, nunca ninguém me falou em plano de saúde, nunca ninguém veio falar comigo para nada: 'você vai participar disso; você vai ter direito a isso; os seus direitos são esses; a Elétrica te dá isso; a Elétrica te proporciona isso”. Essa percepção contrasta com o depoimento do E19 (Gerente de Vendas Europa), atual expatriado em Portugal, que embora não tenha necessitado de apoio da GRH portuguesa, acredita que terá suporte quando solicitar: "se eu preciso de qualquer coisa, independente se precisar de médico, quando eu precisar tenho todo apoio aqui. Em termos de línguas, se precisar de um curso de inglês, qualquer língua que já falo ou que não falo, eles conseguem ajudar também. Eu nunca pedi, mas, com certeza, vão ajudar”.

Embora a empresa tenha consciência de que a comunicação entre as unidades é uma função da GRHI (Schuler, 2000; Taylor et al., 1996), é observado que a “comunicação é um pouco reativa; quando há uma demanda, eles entram em contato com a gente" (E16 Analista de GRHI Brasil). Isso ocorre porque a área tem um papel burocrático e de consultoria e implica em uma menor circulação de informações entre as unidades, contribuindo para um processo ainda imaturo de internacionalização da GRH e, consequentemente, da empresa (Bartlett \& Ghoshal, 2000; Quintanilla et al., 2008; Ando, 2011).

A imaturidade da GRHI também está relacionada com a sua incorporação à área corporativa, focando somente nos diretores da empresa e esquecendo-se dos outros empregados. No caso, a GRHI do Brasil está focada nos expatriados e na "gestão de carreira de todos [diretores]. Cuida da parte de reajustes salariais das estruturas das unidades comerciais, da parte salarial e de benefícios dos diretores, independente se são expatriados ou se são nativos" (E11 - Diretor de GRH Corporativa Brasil). Enquanto diversos estudos criticam que a função da GRHI é limitada ao cuidar apenas dos expatriados (Schuler, 2000; Taylor et al., 1996; Quintanilla, 2002), a GRHI da Elétrica limita-se aos cargos corporativos, sem ampliar a sua visão para toda organização de maneira global, o que pode tornar lento o processo de internacionalização. 
É revelado o direcionamento da GRHI em conhecer as práticas que são utilizadas no exterior. O E13 (Vice-Presidente EUA), o E15 (Ex-Diretor Internacional Brasil) e o E11 (Diretor de GRH Corporativa Brasil) abordaram o projeto Elétrica Knowledge que foi desenvolvido para propiciar o conhecimento em todas as unidades. É “um depositário de procedimentos e processos que tenta cumprir aquilo que é o básico, que é individual. Ele dá os exemplos e tu consegues enxergar o que os outros países têm como prática e aí tu podes fazer as adaptações que tu necessitar" (E13 - Vice-Presidente EUA). Porém, o E16 (Analista de GRHI Brasil) relata que esse projeto não contempla a empresa em uma perspectiva geocêntrica, mas em uma maneira etnocêntrica. O projeto que poderia impulsionar a gestão de conhecimento global da empresa é meramente informativo, para que as outras unidades saibam como executar os processos que são feitos na matriz, contribuindo para uma disseminação e imposição das práticas da matriz (Pudelko \& Harzing, 2007; Quintanilla et al., 2008) e a ausência de uma GRH comparativa.

Deste modo, a GRHI não desempenha a sua função de promover práticas globais (Schuler, 2000; Schuler et al., 1993; Smale, 2008; Edwards et al., 2013; Schuler et al., 2002; Boxall et al., 2007) e nem de gerir os empregados internacionalmente. Também é relapsa em formalizar o conhecimento dos expatriados que, após o retorno de uma experiência internacional, adquiriram conhecimento de mercado, podendo, portanto, traçar novas estratégias de mercado, a partir do trabalho desempenhado no exterior (Gallon et al., 2014).

A perspectiva etnocêntrica da GRH também é identificada na especificação da presença de um empregado brasileiro na gestão da subsidiária (Kim \& Gray, 2005; Oliveira \& Borini, 2010). É uma estratégia adotada pelas empresas no início das operações internacionais, principalmente em mercados dos quais não têm muito conhecimento (Bartlett \& Ghoshal, 2000) e para implantar a cultura e objetivos corporativos (Kim \& Gray, 2005), fato ainda corrente na Elétrica. É salientado que dependendo do contexto e das oportunidades de mercado, há maior ou menor propensão para expatriar, pois nem sempre a presença de um expatriado está relacionada com o ajuste ao mercado. Desse modo, o etnocentrismo da Elétrica de querer gerir as empresas do exterior com profissionais de origem da matriz nem sempre é implantado.

O etnocentrismo da matriz também foi apontado em outros estudos realizados na Elétrica (Cyrino \& Barcellos, 2006), visto a comunicação unidirecional (da matriz para a subsidiária), a forte hierarquia e a falta de oportunidades de intercâmbio entre as unidades do exterior. No entanto, os entrevistados sinalizam que a GRH está amadurecendo com a 
troca de alguns diretores brasileiros por um profissional local, saindo do posicionamento etnocêntrico e buscando uma perspectiva policêntrica das unidades. Os brasileiros que foram enviados, em um primeiro momento, para estruturar as áreas, já estão sendo substituídos por locais, a fim de dar mais autonomia para a unidade.

Os entrevistados também relataram a rotação de brasileiros em cargos corporativos no exterior para outras unidades estrangeiras, para futuramente voltarem para a matriz e assumirem cargos de direção, como relata o E14 (Assistente Técnico Europa): "tivemos um diretor na França 10 anos, brasileiro, que agora foi para Alemanha, dado que o diretor da Alemanha foi para Áustria. Então, foi colocado um diretor francês, uma pessoa que nem era da Elétrica. Foi contratado um externo porque tinha um bom conhecimento do mercado, bons contatos, ser local”.

Essa configuração de expatriação é denominada patriação (Harvey \& Novicevic, 2006) e sinaliza uma perspectiva geocêntrica (Vance \& Paik, 2006). Apesar de a GRH da Elétrica sinalizar a perspectiva geocêntrica para os cargos estratégicos no exterior, o predomínio de gestores brasileiros na matriz, sem a presença de empregados das subsidiárias na matriz - impatriados (Harvey et al., 2000; Rego \& Cunha, 2009) - mostra como a empresa está voltada para o mercado brasileiro, sem aproveitar as diversidades da internacionalização.

De modo geral, há algumas práticas que permitem a divulgação do que é feito nas unidades, como a revista e a intranet da empresa, mas ainda são práticas incipientes. Assim, a perspectiva geocêntrica é tímida e confirma o posicionamento policêntrico com a identificação pontual das práticas de GRH existentes no mercado internacional e não de maneira global (Pudelko \& Harzing, 2007; Edwards et al., 2013), como relata o E11 (Diretor de GRH Corporativa Brasil):

A GRH daqui tem um radar maior na faixa de desenvolvimento. Precisamos saber quem são as pessoas que estão aqui. O que estamos fazendo hoje é, pegando tanto a parte de remuneração quanto a parte de desenvolvimento e criando um sistema único, mas não temos ainda. Planejar e contratar, cada unidade lá fora faz da sua forma. Eu não vou dizer: 'tu tem que fazer entrevista de seleção em cinco unidades'. Se ele quiser planejar ou não esse critério é de acordo com o orçamento deles. Detalhe que isso, a gente não interfere, quem interfere é a área de controladoria. Então, em 
termos de GRH, o principal é o desenvolvimento de pessoas e remuneração. O que precisa melhorar como GRHI é o conhecimento na mão das pessoas, nativos e não nativos; a gestão, os contratos de trabalho; as práticas de benefícios e remuneração em todos os países. Não tentar uniformizar; tomar conhecimento, para ver o que pode interferir, e obviamente otimizar. Desenvolver práticas mais focadas à GRH, tomar conhecimento e ver como estão sendo conduzidas, são os principais pontos.

O depoimento anterior mostra que a GRH da matriz não tem influência no planejamento da GRH das unidades, ou seja, no planejamento estratégico é decidido os recursos que cada unidade receberá e, a partir disso, a unidade realoca o recurso por área. Essa estrutura representa a dispersão das GRH, evidenciando a ausência de uma GRHE, a qual deve integrar e articular políticas, práticas e processos entre si, a fim de alinhar as estratégias e práticas da área à estratégia empresarial como um todo (Schuler, 2000; Tanure et al., 2007; Kim \& Gray, 2005).

Esse contexto gera um posicionamento passivo da GRH das unidades frente à GRHE, como relata o E16 (Analista de GRHI Brasil): “o sistema [de GRH] roda legal na Índia, México e Chile. Tem outras unidades que usam esse sistema de GRH, mas não tem uma participação da GRH tão ativa. A gente usa o mesmo sistema, mas não significa que as políticas deles estejam alinhadas com a GRH corporativa”. Assim, a empresa perde em posicionamento estratégico global, pois suas políticas e práticas não são globalmente construídas, visto o pequeno espaço da GRH das subsidiárias na estratégia global (Quintanilla et al., 2008; Kim \& Gray, 2005), implicando em uma limitada experiência internacional (Ando, 2011). Sendo assim, um dos desafios da GRHI é auxiliar nessa interface, alinhando os processos internos das subsidiárias, para que eles sejam apoio e não empecilho à colaboração externa (Tanure et al., 2007).

Para o novo plano estratégico da Elétrica - projeto '20-20': faturamento de 20 bilhões de reais até o ano de 2020 -, espera-se que a empresa busque desenvolver uma GRHE para dar o suporte necessário para a empresa, como pontua o E16 (Analista de GRHI Brasil): "ela quer sair de sete bilhões de reais e quer chegar em 20 bilhões de reais. O que representa triplicar o faturamento? Em termos de GRH, representa mais ou menos duplicar o número de funcionários da empresa. Então, se hoje ela tem 25 mil funcionários, ela vai ter que chegar 
a 50 mil funcionários. Então, qual é o desafio hoje da GRH? 50 mil funcionários. Tem que preparar a gestão da empresa”.

\section{Análise da Gestão de Recursos Humanos da Empresa Plástico}

A Plástico produz embalagens rígidas de plástico para algumas das empresas mais reputadas no mundo, nos setores de bebidas e alimentação, higiene pessoal, higiene da casa e óleos e lubrificantes. Foi fundada em 1976 e, há mais de 30 anos, é pioneira no mundo no desenvolvimento da produção in-house, fornecendo embalagens de plástico just-in-time, em unidades integradas às fábricas dos clientes. Ela faturou 468 milhões de euros em 2015, gerindo 59 fábricas, com cerca de dois mil trabalhadores em 16 países (Empresa Plástico, 2016).

A GRH da matriz tem uma estrutura madura com políticas e práticas definidas, inclusive aquelas relacionadas à expatriação - muito em função de ter sido a primeira fábrica a iniciar este processo e por ser a localidade que mais envia empregados ao exterior -, com duas pessoas responsáveis pelos expatriados que respondem à GRHI (em Londres). Na GRH das subsidiárias, há um gestor que acumula a função da GRHI.

A GRH global é descentralizada da matriz e, por isso, tem a sua estrutura física sediada em Londres - centro de negócios da Europa - a fim de sinalizar que não há uma cultura portuguesa a ser disseminada. A GRH global está voltada para os cargos de gestão, principalmente, quando se trata do contexto internacional, e tem desenvolvido ações para a troca de práticas de GRH entre as unidades: "tem muito isso, disseminação da prática, da cultura e dos conhecimentos" (E1 - CEO e sócio fundador).

Consoante a esse depoimento e no intuito de agregar funções à GRH global, há a demanda pela unificação dos processos das unidades para "que sejam feitos em cada país, mas que depois sejam centralizados em nós [GRH]” (E4 - Analista de GRHI). O E7 (Gerente GRH Brasil) expõe que, na última reunião global, a qual reuniu em Londres os gestores de GRH das diversas unidades, a tendência de implantação das práticas globais voltadas para a GRH foi o principal foco de debate. No entanto, a GRH global tem a perspectiva voltada para o contexto internacional, muito em função do vínculo da GRHI com a sua estrutura, o que implica em gerenciar práticas de diferentes unidades e não em fomentar práticas globais (Quintanilla et al., 2008; Ando, 2011; Pudelko \& Harzing, 2007; Bartlett \& Ghoshal, 1998; Schuler et al., 2002; Smale, 2008). 
Para tanto, a GRHI apresenta uma estrutura, mas não há procedimentos documentados para a expatriação e não oportuniza a conversa entre as GRH das unidades, a fim de contribuir para a internacionalização das práticas, sendo esse o atual papel da GRH global/ comparativa (Schuler, 2000). É, por tanto, uma área focada na operacionalização da expatriação, não apresentando maiores contribuições, o que contraria a literatura, a qual ressalta que a GRHI, além de ser responsável pelos expatriados, deve conectar a empresa a um contexto mais amplo - a GRH global - e ser o meio de ligação na coordenação entre as diversas práticas da GRH doméstica das subsidiárias (Taylor et al., 1996).

Identifica-se, portanto, a presença de uma GRH global, internacional e doméstica, de acordo com a concepção de Boxall et al. (2007) e Schuler (2000). A GRH global carece de um alinhamento de papéis com a GRHI para que a primeira possa desenvolver estratégias globais. A GRHI, que está envolvida com a tramitação burocrática da expatriação, deve dar maior suporte à comunicação e troca de conhecimento entre as GRH das subsidiárias.

No que concerne às subsidiárias, a GRH doméstica brasileira tem uma estrutura independente da GRH da matriz e global e apresenta uma estrutura operacional com processos e práticas organizados em modo de departamento de pessoal. O E7 (Gerente GRH Brasil) observa que cada país é uma unidade da organização, logo, o Brasil tem uma GRH (em São Paulo) responsável pelas diversas fábricas no Brasil. Desse modo, "as unidades ficaram carentes [pois], a GRH é toda corporativa. A gente não tem nenhuma pessoa nas unidades que cuide de GRH” (E6 - Analista GRH Brasil). A E6 (Analista de GRH Brasil) observa que os empregados só percebem a existência da área quando é feito algum comunicado geral ou há recebimento do pagamento.

Os gestores de GRH relatam que a estrutura corporativa da GRH brasileira tem o intuito de deixar a área mais estratégica. Foi contratada uma consultoria para redesenhar os procedimentos para "ter uma GRH, além de estratégica, mais ativa, mais presente nas fábricas" (E6 - Analista GRH Brasil). No entanto, as práticas da GRH brasileira estão voltadas para a GRH doméstica, como o desenvolvimento de treinamento, pesquisa de clima e gestão de carreira. Isto sinaliza o recente amadurecimento tático da área, o qual contribuirá para seu papel mais atuante nas fábricas.

Por tanto, a GRH brasileira carece de identificação de seu papel nas fábricas, expondo um papel ora corporativo, ora de departamento pessoal. No entanto, ela está desenvolvendo uma perspectiva estratégica, a partir do estreitamento das relações com a GRH global, mas carece de suporte diário, nas fábricas brasileiras, deixando de desenvolver políticas e 
práticas de GRH. Isso implica o desconhecimento da GRH sobre o quadro de pessoas e as competências que a Plástico Brasil pode disponibilizar para a estratégia global.

Quanto ao posicionamento da GRH, o E4 (Analista de GRHI) e o E7 (Gerente GRH Brasil) veem que a disseminação de políticas e práticas ocorrem de forma incremental. No início, é implantado um pacote de práticas da matriz e, aos poucos, vai sucedendo a troca de informações. Isso é coerente com a orientação etnocêntrica (Vance \& Paik, 2006), comum às multinacionais no início da sua internacionalização, devido à imaturidade da organização relativa a esse processo (Bartlett \& Ghoshal, 2000; Quintanilla et al., 2008; Ando, 2011).

Embora seja ressaltada a participação dos expatriados para auxiliar na abertura de unidades expatriados e para reduzir a dependência da subsidiária em relação à matriz (Wang et al., 2009; Vance \& Paik, 2006; Kim \& Gray, 2005), a Plástico tem adotado uma perspectiva policêntrica (Vance \& Paik, 2006), como relata o E1 (CEO e sócio-fundador):

'Em Roma sê romano': se queremos ir para um mercado, nós temos de respeitar as regras desse mercado e não o contrário. Tentamos uma estratégia e uma política diferente dos outros que é: acreditamos nos valores locais. É importante, na fase inicial, pegar, mandar dois portugueses. Serviu muito. (...). Também, é muito importante ter indígenas. É muito importante o que houve no Brasil, um brasileiro a gerir lá. Que, na Inglaterra, seja um inglês. E que, no Vietnã, seja um vietnamita. Por quê? Nós temos uma relação muito íntima com os nossos clientes. Portanto, dentro das fábricas exige muita comunicação. E é fundamental. Na segunda-feira, um português vai querer saber e discutir os jogos de futebol do final de semana. Um carioca vai querer discutir como é que foi de praia no final de semana. O inglês vai querer saber se você ficou bêbado só sábado ou sábado e domingo. É, e isto aí é algo que não podemos aprender, é cultural. Isso é falar das equipes, dos times, da praia, que em Ipanema, no posto 9 ou no posto 12, no posto 7 , existe essa forma de poder dialogar, de ver essa fluidez de comunicação. Eu estou falando que é fundamental alguém que saiba, na segunda-feira, falar dos mesmos problemas que todos os outros também têm. 
Apesar de a unidade do Brasil ter 20 anos, a GRH em São Paulo ainda recorre à matriz para o desenvolvimento de práticas: "existem as trocas de práticas, mas o que eu vejo é que nós ainda estamos mais aprendendo com eles” (E7 - Gerente GRH Brasil). Isso mostra que a matriz nem sempre impõe as práticas, mas serve como suporte para ajudar a desenvolver as áreas das unidades, corroborando para uma GRH policêntrica. Além disso, há maior direcionamento para a circulação de informações e práticas, não necessariamente vindas da matriz, visto a atuação da GRH global. Isso mostra que a presença da GRH global desempenha um papel importante na implantação das práticas de GRH (Edwards et al., 2013) e incentivo para a troca de informações.

A GRH global sinaliza que trabalhar em qualquer parte do mundo é uma possibilidade para qualquer empregado da Plástico. Além de mostrar o amadurecimento da área em perspectiva global, essa é uma característica da GRH geocêntrica (Vance \& Paik, 2006), na qual os empregados têm a possibilidade de ocupar cargos importantes nas unidades da empresa, independente de sua nacionalidade, como relata o E1 (CEO e sócio fundador): "sempre que abre uma nova fábrica, seja em Ho Chi Minh ou em Porto Alegre há um lugar para alguém, para chefe de produção, com essas características, para ganhar tanto, em tal fábrica. Isto é enviado para as 2.200 pessoas que trabalham na Plástico e qualquer pessoa pode candidatar-se a esta vaga”.

A orientação da GRH amadureceu com o aprendizado internacional da empresa, seja pela experiência com a abertura de novas unidades, seja pela diversidade de culturas que compõem a empresa. Esse amadurecimento ocorreu de forma incremental, passando por um rápido posicionamento etnocêntrico, na abertura da unidade, e por um período mais longo, com postura policêntrica. No entanto, agora há um direcionamento da unidade do Brasil (e aparentemente de todas as unidades da Plástico) para o posicionamento geocêntrico.

\section{Implicações Para a Teoria}

Os resultados apontam que a contribuição da GRH é subestimada nas organizações, desenvolvendo um papel operacional (Kim \& Gray, 2005). Também é possível ver que os papéis da GRH, GRHI, GRHE e GRH comparativa se sobrepõem na teoria e na prática, principalmente ao que concerne ao contexto internacional. Por vezes, a GRHI assume o papel da GRH global; por vezes, a GRH global assume o papel de GRHE. A inclusão das 
palavras 'global' e 'internacional' na denominação das áreas causa certa confusão sobre os papéis a serem desempenhados. As organizações sem ter conhecimento prévio, mas com a necessidade latente de ter uma estrutura para atender o meio internacional, criam a GRHI e, posteriormente, a GRH global, sem bem definir seus papéis. O fato de agora serem 'internacional' e 'global' não significa que devem estar orientadas só para o que ocorre fora das dimensões territoriais da empresa, mas devem entender aquela área como uma única estrutura, a qual atende a globalidade da organização, bem como os benefícios e empecilhos dela advindos.

Para tanto, compreende-se que os conceitos estanques que a teoria traz também não se encaixam facilmente quando o assunto é internacionalização e configuração de GRH. Há uma fluidez e dinamicidade organizacional que não permite um empacotamento de uma estratégia e posicionamento da empresa no contexto global. Assim, as variáveis teóricas tendem a ser simplistas e, muitas vezes, não conseguem compreender o contexto internacional (Kim \& Gray, 2005).

Coerente a isso, este artigo contribui para a GRHI com os resultados da gestão brasileira em contraponto com o contexto português. As diferenças contextuais dos dois países possibilitam entender o maior amadurecimento internacional das empresas, bem como analisar a hegemonia das teorias anglo-americanas em GRH. Os modelos teóricos nesta temática são quase que inteiramente baseados nas grandes economias maduras (EUA, Reino Unido e Japão). A forma como essas estruturas e tipologias se aplica às empresas de economias pequenas e desenvolvidas (Austrália) e também as emergentes permanecem desconhecidas. Dado os diferentes contextos institucionais e a internacionalização tardia dessas economias, os modelos mais utilizados pelos pesquisadores podem não ser universalmente úteis (McDonnell et al., 2011).

A partir disso, pode-se entender que as teorias são incipientes para entender o contexto de um país emergente, mesmo no caso do Brasil que tem um modelo americano como referência na gestão empresarial. Por isso, pesquisas nesses contextos são importantes a fim de interromper a difusão de políticas e práticas hegemônicas no contexto empresarial, atendando, principalmente, para a expansão das empresas da Malásia, Cingapura, Coréia do Sul e Rússia que trarão seus próprios modelos de organização a ser seguido (McDonnell et al., 2011). Desta forma, a pesquisa contribui com as especificidades teóricas necessárias para analisar contextos de diferentes organizações que atuam em economias desenvolvidas ou emergentes. 


\section{Implicações Para a Prática}

O contexto do país de origem é o primeiro aspecto a ser percebido na análise. Portugal é um país antigo comparado aos 500 anos de ‘descobrimento' do Brasil. Não há como negar que o Brasil ainda se desenvolve e se descobre como país, enquanto Portugal tem uma história mais longa. A diferença no tamanho territorial entre os países também é muito grande: o Brasil é 96 vezes maior que Portugal. Logo, o Brasil tem um grande mercado interno para comercializar, fazendo com que as empresas brasileiras demorem mais para sair para o exterior. As empresas portuguesas veem o mercado português rapidamente saturado, sendo impulsionadas à internacionalização.

Esses fatores, bem como a burocracia, corrupção, ‘jeitinho brasileiro’, a diferença de infraestrutura, escolaridade e educação básica são aspectos que impactam na internacionalização das empresas brasileiras. Portugal tem educação básica disponível para todos os cidadãos e grande parte dos estudantes, ao concluir o período escolar, domina duas ou três línguas (português, francês e inglês). O Brasil carece de tal formação: mais de 30\% da população adulta (25 - 64 anos) não completaram o ensino fundamental; 81,6\% dos jovens com idade de 18 a 24 anos não têm acesso ao ensino superior; e apenas 12,9\% da população adulta têm curso superior completo (Instituto Brasileiro de Geografia e Estatística (IBGE), 2015). Em contrapartida, em Portugal apenas 30,3\% da população não completaram o ensino básico; 23,8\% da população adulta (25 - 64 anos) têm curso superior completo; e 14\% da população abandonou precocemente a formação (Instituto Nacional de Estatística (INE), 2016).

Tal panorama se reflete em um pequeno grupo de pessoas com fluência em inglês, o que dificulta a expatriação de brasileiros para o exterior e de outras pessoas para o Brasil. A menor frequência da mobilidade do empregado brasileiro acarreta em um grupo técnico menos competitivo nos negócios da empresa e na internacionalização do país, de modo geral, pois há menor tendência de o Brasil receber estrangeiros. Essa situação impede que o conhecimento, que entra e sai do país, seja mais globalizado quando comparado a outros países. O E5 (Diretor Geral da Plástico Brasil) expõe a sua percepção:

Porque poucas falam bem inglês. Por isso, é uma dificuldade. Porque você tem que: 'vamos para a Holanda; vai para a Itália; vai para os EUA' tem que ser fluente, e não 
são. Mesmo em cargo de diretores, um ou dois falam. Há diretores que ainda falam bem inglês, mas se for para gerente, já poucos falam. É, e para baixo, menos ainda. Por isso, eu acho que não ganharam a oportunidade de expatriar. Nem envolve qualidade, porque já para competir ao mesmo cargo com outras pessoas tem que saber falar. A Plástico abre concursos para quem vai para outros países. E eu vejo colegas da Inglaterra irem trabalhar na Malásia, no Vietnã. Colegas da Espanha irem para a Holanda ou Canadá.

Esse depoimento corrobora com outros estudos (Cyrino \& Barcellos, 2006) que apontam o fraco domínio da língua inglesa e a pouca experiência internacional dos executivos e proprietários brasileiros (Rego \& Cunha, 2009; McDonnell et al., 2011) como fator limitante na internacionalização das operações no exterior, bem como na globalização do mercado brasileiro. A comunicação por meio da língua inglesa é importante para atrair investidores estrangeiros. Quando ela não existe, surge a possibilidade de investimento em outras economias emergentes que já têm a fluência nesta língua, como a Índia. Tal situação é corroborada com a fala do E1 (CEO e sócio-fundador da Plástico): "não é como você ir para a Holanda, em que toda gente fala fluentemente inglês. No Brasil, as pessoas que falam línguas, não são muitas. E as que falam, muitas vezes, é um inglês macarrônico, quer dizer, não, não é uma coisa fácil”.

Esse cenário requer que as empresas tenham uma GRH e GRHI que englobem a diversidade internacional e não foquem só nos expatriados. É necessário que elas estejam preparadas para receber os expatriados, os impatriados, os cidadãos do mundo e os empregados de outros países que não têm vínculos com a organização. A partir da promoção da circulação desses diferentes passaportes, as empresas estarão amadurecendo globalmente, bem como contribuindo para o desenvolvimento do contexto brasileiro, deixando-o mais global.

\section{Considerações Finais}

O presente estudo teve o propósito analisar as configurações da GRH na internacionalização de duas organizações multinacionais: uma brasileira e uma portuguesa. 
Os achados formaram a base para entender a estrutura da GRH, conforme a empresa se internacionaliza. A Plástico tem uma estrutura de GRH mais consolidada, apresentando uma GRH global desvinculada da matriz da empresa e o incentivo da movimentação dos empregados entre as unidades, independentemente da sua nacionalidade. Ela conta com a contribuição da GRH das unidades no exterior para desenvolver e consolidar sua cultura global, o que sinaliza um amadurecimento da área e um posicionamento geocêntrico.

A GRHI da Plástico está dentro da GRH global e não tem papel definido, por isso algumas das suas funções se confundem com as da GRH global. Além disso, ela está focada na expatriação, embora não apresente um plano para esse processo com práticas definidas tal como a Elétrica o faz. Isso pode ocorrer por causa da percepção e da estratégia que a Plástico tem para a expatriação. No entanto, não exime a responsabilidade da GRHI de fazer a comunicação com a GRH das outras unidades no exterior.

A Elétrica tem uma GRH etnocêntrica, a qual envia as diretrizes para as subsidiárias no exterior, coerente com o posicionamento de multinacional. Assim, a GRH da subsidiária portuguesa desenvolve atividades burocráticas e operacionais e depende das decisões tomadas na matriz. A GRHI está focada no processo de expatriação, para o qual apresenta políticas e práticas estruturadas, embora careça de maior efetividade dessas práticas. Este fato também está relacionado com a concepção de expatriação da empresa que a concebe como um processo mais formal do que o da Plástico, no qual o empregado tem um contrato com o país de origem e uma previsão de retorno. No entanto, tal como na Plástico, a GRHI deve assumir suas responsabilidades, pois a internacionalização da empresa é ampla e precisa se organizar para não deixar os expatriados sem suporte no exterior. Ressalta-se que, como a Plástico quebra o vínculo empregatício do expatriado com o país de origem e o incorpora na estrutura do país de destino, o empregado não se sente abandonado pela empresa, como acontece em alguns casos da Elétrica.

Coerente a isso, a GRH global da Elétrica é inexistente formalmente, mas há uma política de disseminação de práticas da matriz. As informações entre as unidades são trocadas informalmente, não sendo de conhecimento da empresa. A GRH global poderia construir práticas globais consoante com as unidades no exterior, a fim de incorporar as experiências internacionais na empresa e complementar sua competitividade com esse conhecimento (Schuler, 2000). Assim, ressalta-se que GRH global deve fomentar a difusão de políticas e práticas das subsidiárias a fim de interromper o status quo da matriz e proporcionando conhecimento global na organização (McDonnell et al., 2011). 
Ressalta-se que nos dois casos nos foi possível visualizar uma GRHE ativa. Quanto à internacionalização, a Plástico está 'um passo à frente' da Elétrica, pois tem uma GRH global desvinculada da matriz, dando fluidez aos negócios e incentiva a circulação de empregados entre as unidades independentemente da sua nacionalidade. Já a Elétrica é internacional, mas não é internacionalizada, principalmente, pelo posicionamento etnocêntrico da GRH. No entanto, está desenvolvendo a concepção multinacional, possibilitando às subsidiárias terem maior independência, falta, porém, proporcionarem uma atuação estratégica das subsidiárias.

Ressalta-se que as relações de trabalho no âmbito internacional estão mudando e demandam a movimentação de diversas pessoas para diferentes países, independentemente da sua nacionalidade, inclusive frente à crescente migração (McDonnell et al., 2011) e das diferentes configurações dos expatriados. Mudam-se, portanto, as origens e os vínculos, mas permanecem as pessoas, requerendo uma GRHI com a mesma dinamicidade. As empresas demandam empregados com diversas competências, porém, não apresentam políticas e práticas para tornar isso um diferencial estratégico e, principalmente, não conseguem lidar com tamanha diversidade cultural. No contexto brasileiro, ainda não foi sentida a necessidade de ter uma gestão que englobe os empregados internacionais, pois esses recém vêm voltando de suas expatriações e agora que as empresas estão despertando para entender as implicações de expatriações mal sucedidas, bem como gerir o conhecimento dessas pessoas.

Isso mostra que o conhecimento internacional não está somente no que está sendo realizado no exterior, mas também nas pessoas que circulam pelas diferentes subsidiárias. Para tanto, exige que a GRH e a GRHI tenham um papel mais ativo e estratégico na gestão da empresa (De Ré \& De Ré, 2011; Richey \& Wally, 1998; Kim \& Gray, 2005), deixando de ser uma área meramente burocrática e perpetuando uma gestão global da organização.

\section{Limitações da Pesquisa}

A pesquisa teve como delimitação de estudo: analisar empresas portuguesas e brasileiras, do ramo industrial, internacionalizadas e com processo de expatriação estruturado. Entretanto, algumas limitações surgiram durante a investigação. Nas entrevistas, verificou-se que o modo de entrada no país estrangeiro alterava o controle que a empresa tinha sobre a subsidiária (no caso de aquisições, fusões ou joint ventures) e, por 
isso, algumas decisões - por exemplo, de levar expatriados ou contratar empregados locais -, por vezes, cabia ao sócio estrangeiro (Edwards et al., 2013), não sendo responsabilidade da empresa pesquisada atuar nessa gestão. Por isso, o amadurecimento da subsidiária e a ausência de práticas globais pode estar relacionada com os acordos societários.

Ressalta-se, também, que a pesquisa qualitativa tem como mérito o aprofundamento das informações coletadas, mas carece de uma mensuração a fim de medir o nível de internacionalização GRH (Edwards et al., 2013). A dificuldade de medir resultados é uma das críticas que se tem a GRH o que pode perpetuar a imagem errônea de ser uma área que traz poucos resultados, visto a falta de comprovação matemática dos resultados e da efetividade da área (Barbosa, 2009).

A questão da língua também foi um fator limitante. Embora a língua de ambos os países seja o português, por vezes, os conceitos usados em Portugal são entendidos de modo diferente do que no Brasil. Como os portugueses falam rápido, pode ter ocorrido, na transcrição das entrevistas, alguma eventual falha no entendimento das palavras verbalizadas. Nesse sentido, destaca-se a importância de uma das pesquisadoras ter estudado em Lisboa (Portugal) durante nove meses que antecederam a coleta de dados. Assim, quando as entrevistas foram realizadas, minimizou-se a possibilidade de má interpretação dos significados das expressões locais pela já familiarização com a língua portuguesa. Por mais que a língua portuguesa seja comum entre os países pesquisados, há diferenciações advindas do sotaque, do vocabulário local e do modo diferente de organizar o pensamento, o que foi, inclusive, sinalizado pelos entrevistados que expatriaram para Portugal/ Brasil e apontado em outros estudos (Rocha, Mello, Maculan, \& Pacheco, 2010).

Uma limitação teórica, não exclusiva do presente estudo, mas, de maneira geral, pertinente às pesquisas sobre GRH e internacionalização, realizadas em países emergentes, como o Brasil, é que a literatura utilizada é a americana, havendo poucos estudos bem estruturados, consolidados e contextualizados em países emergentes (Bianchi, 2011). Por mais que se queira embasar teoricamente a pesquisa em estudos brasileiros, as principais teorias são da vertente americana (Pudelko \& Harzing, 2007; McDonnell et al., 2011; Bianchi, 2011). Consequentemente, não há a devida compreensão do contexto, visto que a realidade das empresas estrangeiras não é necessariamente convergente com aquela na qual as empresas brasileiras estão inseridas. Ainda não há desenvolvimento teórico sobre GRHI e internacionalização consolidado em contextos emergentes. As pesquisas acabam, 
portanto, buscando respaldo teórico em contextos americanos e europeus, apresentando resultados não tão consoantes ou esperados da teoria embasada.

\section{Sugestões Para Pesquisas Futuras}

Entre as diversas estratégias de internacionalização, orientações de gestão, a GRH deve construir um novo papel para as estratégias internacionais. A GRH demanda ser menos reativa, implicando em uma atuação mais estratégica e contextual (De Ré \& De Ré, 2011; Richey \& Wally, 1998; Kim \& Gray, 2005), o que poderia ser fortalecido com pesquisas nessa área (Lengnick-Hall et al., 2009; Armond et al., 2016). Há necessidade, também, de se compreender a GRH de maneira mais crítica, frente à realidade teórica e empírica das organizações (Fenwick, 2005) a fim de entender as relações informais, as relações de poder (Fenwick, 2005), necessidades individuais dos gestores (Becker-Ritterspach \& Dörrenbächer, 2011; Dörrenbächer \& Geppert, 2009) que impactam na gestão empresarial. Esse olhar mais crítico trará resultados mais aprofundados e próximos da realidade das empresas, perpetuando uma aproximação da academia com as empresas.

Frente aos modelos teóricos sobre internacionalização, também há a necessidade de estudos com maior desenvolvimento empírico (Edwards et al., 2013); e uma análise menos descritiva e mais aprofundada, com a devida relação teórica (McDonnell et al., 2011). Entender qual a contribuição estratégica do processo de expatriação para organização; como a comunicação das GRH afeta o desempenho da organização (Kim \& Gray, 2005); como os gerentes das subsidiárias identificam as práticas que devem ser implantadas (Edwards et al., 2013); como as empresas operam e se comportaram no contexto internacional; como e por que a prática de GRH varia entre as multinacionais com o mesmo país de origem; como a GRH e as suas práticas se desenvolvem nas mesmas organizações em diferentes países; qual o papel da GRH desempenhado e como as funções se diferem nas subsidiárias; qual o impacto do papel da subsidiária na GRH; e a influência das questões societárias empresariais são questões que ainda carecem de respostas na academia (McDonnell et al., 2011; Edwards et al., 2013).

Enfatiza-se, também, a importância de analisar as diferentes configurações assumidas pelos expatriados conforme o amadurecimento e as estratégias internacionais da empresa. A literatura apresenta poucas perspectivas conceituais sobre a expatriação e não há uma discussão, com profundidade, sobre as alterações e as implicações teóricas sobre o 
assunto no contexto internacional. Logo, os estudos não constroem uma teoria, porque apresentam os mesmos conceitos sem discuti-los, o que repercute em pouca contribuição teórica.

Obviamente, os países emergentes também carecem de maior aprofundamento de pesquisa, necessitando serem focos de estudos para consolidar teorias referentes a seus contextos (Schuler et al., 2002; Bianchi, 2011; Pudelko \& Harzing, 2007; McDonnell et al., 2011), principalmente, no que concerne aos estudos de internacionalização de empresas (Bartlett \& Ghoshal, 2006). Também é sugerido estudos comparativos entre países desenvolvidos e economias emergentes - China, Índia, Rússia e Brasil -, visto que as abordagens etnocêntricas (americanas e europeias) já não são sustentáveis no ambiente corporativo globalizado (Pudelko \& Harzing, 2007).

Agradecimentos: À CAPES pelo apoio financeiro. 


\section{Referências}

Ando, N. (2011). Isomorphism and foreign subsidiary staffing policies. Cross Cultural Management: An International Journal, 8(2), 131-14.

Armond, L. P., Côrtes, F. G., Santos, F. A. M., Demo, G., \& Meneses P. P. (2016). Gestão estratégica de pessoas: Revisão da produção nacional de 2006 a 2015 e agenda de pesquisa para o contexto brasileiro. Anais do Encontro Nacional dos Programas de PósGraduação em Administração, Rio de Janeiro, Brasil, 40.

Barbosa, A. C. Q. (2009). Gestão de recursos humanos: Realidade atual e perspectivas. In J. R. SILVA, \& A. C. Q. Barbosa (Orgs). Estado, empresas e sociedade. Um mosaico lusobrasileiro. Lisboa: Edições Colibri.

Bardin, L. (2009). Análise de conteúdo (3. ed.). Lisboa, Portugal: Edições 70.

Bartlett, C. A., \& Ghoshal, S. (1998). Managing Across Borders: The Transnational Solution (2. ed.). London: Random House.

Bartlett, C. A., \& Ghoshal, S. (2000). Going global: Lessons from late movers. Harvard Business Review, 78(2), 133-142.

Bartlett, C. A., \& Ghoshal, S. (2006). Organizar para a efetividade mundial: A solução transnacional. In B. Tanure, \& R. G. Duarte. (Orgs.). Gestão Internacional. São Paulo: Saraiva.

Becker-Ritterspach, F., \& Dörrenbächer, C. (2011). An Organizational Politics Perspective on Intra-firm Competition in Multinational Corporations. Management International Review, 51, 533-559.

Bianchi, E. M. P. G. (2011). Gestão e Carreira Internacional. Repatriação: Construindo elos entre ciclos. Anais do Encontro Nacional dos Programas de Pós-Graduação em Administração, Rio de Janeiro, Brasil, 35.

Boxall, P., Purcell, J., \& Wright, P. M. (2007). Human resource management: Scope, analysis and significance. In P. Boxall, J. Purcell, \& P. M. Wright. (Eds.). The Handbook Of Human Resource Management, 1-16. Oxford: Oxford University Press. 
Cyrino, A. B., \& Barcellos, E. P. (2006). Estratégias de Internacionalização: evidências e reflexões sobre as empresas brasileiras. In B. Tanure, \& R. G. Duarte (Orgs.). Gestão Internacional. São Paulo: Saraiva.

De Ré, C. A., \& De Ré, M. A. (2011). Processos do sistema de gestão de pessoas. In C. Bitencourt (Org.). Gestão Contemporânea de Pessoas. Porto Alegre: Editora Bookman.

Dickman, M., \& Doherty, N. (2008). Exploring the career capital impact of international assignments within distinct organizational contexts. British Journal of Management, 19, $145^{-161 .}$

Dörrenbächer, C., \& Geppert, M. (2009). Subsidiary staffing and initiative-taking in multinational corporations: A socio-political perspective. Personnel Review, 39(5), 600621.

Edwards, P. K., Sánchez-Mangas, R., Tregaskis, O., Lévesque, C., McDonnell, A., \& Quintanilla, J. (2013). Human resource management practices in the multinational company: A test of system, societal, and dominance effects. Industrial and Labor Relations Review, 66(3), Spring.

Empresa Elétrica (2011). Material interno da empresa, Lisboa, Portugal, Empresa Elétrica.

Empresa Plástico (2016). Material interno da empresa, Lisboa, Portugal, Empresa Plástico.

Fenwick, T. (2005). Conceptions of critical HRD: Dilemmas for theory and practice. Human Resource Development International, 8(2), 225 - 238.

Freitas, M. E. de., \& Dantas, M. (2011). O Estrangeiro e o novo grupo. Revista de Administração de Empresas, 51(6), 601-608.

Gallon, S., \& Antunes, E. D. D. (2013). O Processo de expatriação na estratégia organizacional. Anais Congresso Instituto Franco - Brasileiro de Administração de Empresas (IFBAE), Tours, França, 7.

Gallon, S., Scheffer, A. B. B.. \& Gallon, I. (2014). Os desafios da repatriação: Um estudo de caso em uma empresa multinacional do Sul do Brasil. Revista Ciências Administrativas, $20,313-346$. 
Harvey, M., \& Novicevic, M. (2006). The evolution from repatriation of managers in MNEs to "patriation" in global organizations. In G. K. Stahl, \& I. Björkman. Handbook of research in international human resource management. Massachusetts: Edward Elgar.

Harvey, M., Ralston, D., \& Napier, N. (2000). International relocation of inpatriate managers: assessing and facilitating acceptance in the headquarters organization. International Journal of Intercultural Relations, 24, 825-846.

Instituto Nacional de Estatística (INE). (2016). Recuperado de http://www.ine.pt

Instituto Brasileiro de Geografia e Estatística (IBGE). (2015). Recuperado de https://www.ibge.gov.br/estatisticas-novoportal/sociais/educacao/9221-sintese-deindicadores-sociais.html?\&t=resultados

Janghorban, R., Roudsari, R. L., \& Taghipour, A. (2014). Qualitative Stud Health wellbeing. Recuperado de http://dx.doi.org/10.3402/qhw.v9.24152

Johnston, S., \& Menguc, B. (2007). Subsidiary size and the level of subsidiary autonomy in multinational corporations: A quadratic model investigation of australian subsidiaries. Journal of International Business Studies, 38(5), 787-801.

Jornal i. (2011). Entrevistado 1: "O maior problema que existe em Portugal é a classe empresarial”. Recuperado de http://www.ionline.pt/artigos/dinheiro/entrevistado1maior-problema-existe-portugal-classe-empresarial

Kim, Y., \& Gray, S. J. (2005). Strategic factors influencing international human resource management practices: An empirical study of australian multinational corporations. International Journal of Human Resource Management, 16(5), 809-830.

Lee, S., \& Williams, C. (2007). Dispersed entrepreneurship within multinational corporations: A community perspective. Journal of World Business, 42(4), 505-19.

Lengnick-Hall, M. L., Lengnick-Hall, C. A., Andrade, L. S., \& Drake, B. (2009). Strategic human resource management: the evolution of the field. Human Resource Management Review, 19, 64-85.

Mccall Júnior, M., \& Hollenbeck, G. P. (2003). Desenvolvimento de executivos globais. As lições da experiência internacional. Porto Alegre: Bookman. 
McDonnell, A., Stanton, P., \& Burgess, J. (2011). Multinational enterprises in Australia: two decades of international human resource management research reviewed. Asia Pacific Journal of Human Resources, 49(1), 9-35.

Nardi, L. M. R. (2015). O perfil do profissional auto-expatriado e práticas de gestão de pessoas. (Dissertação de Mestrado). Faculdade de Administração, Contabilidade e Economia. Pontifícia Universidade Católica de Porto Alegre, Porto Alegre.

Oliveira, M. M., \& Borini, F. (2010). Estratégias e mecanismos para transferência de conhecimento nas multinacionais brasileiras. In A. Fleury (Org.). Gestão Empresarial para a internacionalização das empresas brasileiras. São Paulo: Atlas.

Pudelko, M., \& Harzing, A.-W. (2007). Country-of-origin, localization, or dominance effect? An empirical investigation of HRM practices in foreign subsidiaries. Human Resource Management, 46(4), 535-559.

Quintanilla, J. (2002). Dirección de recursos humanos em empresas multinacionales: las subsidiarias al descubierto. Madrid: Prentice Hall.

Quintanilla, J., Susaeta, L., \& Sanchez-Mangas, R. (2008). The diffusion of employment practices in multinationals: 'Americanness' within US MNCs in Spain? Journal of Industrial Relations, 5o(5), 680-696.

Rego, A., \& Cunha, M. P. E. (2009). Manual de gestão transcultural de recursos humanos. Lisboa: Editora RH.

Richey, B., \& Wally, S. (1998). Strategic human resource strategies for transnationals in Europe. Human Resource Management, 8(1), 79-97.

Rocha, A., Mello, R. C., Maculan, A. M. D., \& Pacheco, H. F. (2010). Ivia: crescimento e internacionalização. Revista de Administração Contemporânea, 14(6), 1158-1170.

Schuler, R. S. (2000). The internationalization of human resource management. Journal of International Management, 6, 239-260.

Schuler, R. S., Budhwar, P. S., \& Florkowski, G. W. (2002). International human resource management: review and critique. International Journal of Management Reviews, 4(1), 41-70. 
Schuler, R. S., Dowling, P. J., \& De Cieri, H. (1993). An integrative framework of strategic international human resource management. Journal of Management, 19(2), 419-459.

Smale, A. (2008). Global HRM integration: a knowledge transfer perspective. Personnel Review, 37(2), 145-164.

Tanure, B., Evans, P., \& Pucik, V. (2007). A gestão de pessoas no Brasil: Virtudes e pecados capitais: Estudos de Caso. Rio de Janeiro: Elsevier.

Taylor, S., Beechler, S., \& Napier, N. (1996). Toward an integrative model of strategic international human resource management. Academy of Management Review, 21,959985 .

Ulrich, D. (2000). Introdução. In D. Ulrich (Org.) Recursos Humanos Estratégicos. Novas perspectivas para os profissionais de RH. São Paulo: Editora Futura.

Vance, C. M., \& Paik, Y. (2006). Managing a global workforce: Challenges and opportunities in international human resource management. New York: M. E. Sharpe.

Wang, S., Tong, T. W., Chen, G., \& Kim, H. (2009). Expatriate utilization and foreign direct investment performance: The mediating role of knowledge transfer. Journal of Management, 35(5), 1181-1206.

Yin, R. (2010). Estudo de caso: planejamento e métodos (3. ed.). Porto Alegre: Bookman. 